\title{
Cloning and characterization of a shrimp clip domain serine protease homolog (c-SPH) as a cell adhesion molecule
}

\author{
Chun-Yu Lin ${ }^{\mathrm{a}}$, Kuang-Yu Hu${ }^{\mathrm{b}}$, Shih-Hu Ho ${ }^{\mathrm{a}}$, Yen-Ling Song ${ }^{\mathrm{a}, \mathrm{c}, *}$ \\ ${ }^{a}$ Institute of Zoology, National Taiwan University, Taiwan \\ ${ }^{\mathrm{b}}$ Department of Biochemistry, National Defense Medical Center, National Defense University, Taiwan \\ ${ }^{\mathrm{c}}$ Department of Life Science, National Taiwan University, Taiwan
}

Received 22 December 2005; received in revised form 19 March 2006; accepted 21 March 2006

Available online 27 April 2006

\begin{abstract}
Clip domain serine protease homologs (c-SPHs) are involved in various innate immune functions in arthropods such as antimicrobial activity, cell adhesion, pattern recognition, opsonization, and regulation of the prophenoloxidase system. In the present study, we cloned a c-SPH cDNA from tiger shrimp (Penaeus monodon) hemocytes. It is $1337 \mathrm{bp}$ in length with a coding region of $1068 \mathrm{bp}$ consisting a protein of 355 amino acid residues. The deduced protein includes one clip domain and one catalytically inactive serine protease-like (SP-like) domain. Its molecular weight is estimated to be $38 \mathrm{kDa}$ with an isoelectric point of 7.9. The predicted cutting site of the signal peptide is located between $\mathrm{Gly}^{21}$ and $\mathrm{Gln}^{22}$. We aligned 15 single clip domain SPH protein sequences from 12 arthropod species; the identity of these clip domains is low and that of SP-like domains is from $34 \%$ to $46 \%$. The conserved regions are located near the amino acid residues which served as substrate interaction sites in catalytically active serine protease. Phylogenetically, the tiger shrimp c-SPH is most similar to a low molecular mass masquerade-like protein of crayfish, but less similar to c-SPHs in Chelicerata and Insecta. Nested reverse transcription polymerase chain reaction (RT-PCR) revealed that c-SPH mRNA is expressed most in tissues with the highest hemocyte abundance. Antimicrobial and opsonization activities of the molecule were not detected. The expression of c-SPH mRNA in hemocytes was up-regulated at the 12-day post $\beta$-glucan immersion. Recombinant c-SPH could significantly enhance hemocyte adhesion. The result suggests that the shrimp c-SPH protein plays a role in innate immunity.
\end{abstract}

(C) 2006 Elsevier Ltd. All rights reserved.

Keywords: Clip domain; Serine protease homolog; Tiger shrimp; Cell adhesion

\section{Introduction}

The innate immune system in invertebrates which

Abbreviations: SP, serine protease; C-SPH, clip domain SP homolog; HLS, hemocyte lysate supernatant; ProPO, prophenoloxidase

*Corresponding author. Institute of Zoology, National Taiwan University, Taipei, 106, Taiwan. Tel.: +886233662455; fax: +886223660243 .

E-mail address: song@ntu.edu.tw (Y.-L. Song). is important in protecting the host from pathogen infection involves different factors such as physical barrier, bacteria clearance, encapsulation, clotting reactions, prophenoloxidase system, reactive oxygen intermediates, and antimicrobial activity. The innate immune system uses a variety of pattern 
recognition molecules to detect a pathogen-associated molecule pattern (PAMP) and to transduce signals during pathogen invasion. After receiving the signals, hemocytes are activated and degranulate defense molecules against the pathogens. Cell adhesion is the first step in many cellular responses such as hemocyte spreading, nodule formation, encapsulation, hemocyte aggregation, and phagocytosis.

In 1995, a clip domain serine protease homolog (c-SPH), named masquerade (mas), was found in Drosophila melanogaster. It was shown to stabilize muscle attachment in the Drosophila embryo [1]. Since then, more mas-like c-SPH molecules have been discovered in arthropods. These c-SPH molecules share common structural features, such as disulfide knotted clip domain(s) at the $\mathrm{N}$ terminus of the polypeptide chain and a catalytically inactive serine protease-like domain at the $\mathrm{C}$ terminus. A clip domain, named according to the schematic form of a paper clip [2], features the pattern of three disulfide bonds described by Muta et al. [3]. The clip domain may be involved in protein-protein interactions, regulation of the protease activity, and even antimicrobial activity [4]. The overall sequence similarity between different clip domains is low, but the six Cys residues are strictly conserved. All serine protease-like domains in mas-like c-SPHs are catalytically inactive because of the substitution of Gly for the catalytic Ser residue. These c-SPHs are synthesized as precursors with signal peptides and activation cleavage sites. Released either immediately after synthesis or following a triggering signal, c-SPHs may require a proteolytic activation. After the proteolytic activation, the $\mathrm{N}$ terminus and the $\mathrm{C}$ terminus of the c-SPH are linked by an inter-domain disulfide bond. Recently, c-SPH molecules with different repeats of the clip domain have been reported. The high-mass c-SPHs in fruit fly and crayfish possess five and seven clip domains, respectively. Most of the c-SPHs cloned so far belong to low molecular mass c-SPHs and possess only one clip domain. It is not clear whether the number of clip domains determines the activity.

The first study describing the crystal structure of a c-SPH (Holotrichia diomphalia PPAF-II) was recently published by Piao et al. [5]. The clip domain of the Hdi PPAF-II has shown to be a protein interaction module interacting with proPO via the structural central cleft. In c-SPH, there are three unique structural features in comparison to catalytically active clip domain serine protease (c-SP). Those features include four signature regions (I-IV), one calcium-binding loop which partially overlaps with signature region II in serine proteaselike domain, and one alpha helix at $\mathrm{N}$ terminus.

C-SPHs are involved in other biological roles which are antimicrobial activity, hemocyte adhesion, pattern recognition, opsonization, and regulation of the prophenoloxidase system. Limulus factor $\mathrm{D}$, a c-SPH discovered in large granules of hemocytes in Tachypleus tridentatus, was shown to possess antimicrobial activity against Gram-negative bacteria [6]. A mas-like protein discovered in Pacifastacus leniusculus hemocytes was shown to be involved in granulocyte adhesion, pattern recognition, and opsonization [7,8]. It has also been demonstrated that c-SPHs of Holotrichia diomphalia, Tenebrio molitor, Manduca sexta, Cotesia rubecula, and Callinectes sapidus participate in the regulation of the prophenoloxidase system [9-14]. The Lonomia oblique prophenoloxidase activating factor 1, the factor D-like protein of Dermacentor variabilis, and the low molecular mass mas-like protein of Pacifastacus leniusculus are not well characterized functionally, but they are assumed to be immune-related based on their localization or activation response to pathogens or PAMP in mRNA expression or protein release [15-17].

In the present study, we cloned and characterized a shrimp c-SPH molecule and discussed its tissue distribution, expression profile, and cell adhesion activity.

\section{Materials \& methods}

\subsection{Hemocyte cDNA preparation}

Tiger shrimp ( $P$. monodon), with a body weight of $10-15 \mathrm{~g}$ were purchased from a hatchery in southern Taiwan. Following acclimation for two weeks, shrimp hemolymph was withdrawn using a $1 \mathrm{~mL}$ syringe with a 26 gauge-needle and an anticoagulant $(0.1 \mathrm{M}$ sodium citrate, $0.4 \mathrm{M}$ sucrose, and $0.01 \mathrm{M}$ Tris- $\mathrm{HCl} ; \mathrm{pH} 7.6 ; 780 \mathrm{mOsm} / \mathrm{kg}$ ). The withdrawn sample was centrifuged at $700 \mathrm{~g}$ for $5 \mathrm{~min}$ at $4{ }^{\circ} \mathrm{C}$ and the pellet was harvested. The total hemocyte RNA was extracted using Trizol reagent (Gibco BRL, USA), and cDNA was synthesized using the ThermoScript ${ }^{\mathrm{TM}}$ RT-PCR system according to the manufacturer's instruction (Invitrogen Life Technologies). 


\subsection{RT-PCR of the serine protease-like (SP-like) domain}

The hemocyte cDNA was used as a template for PCR amplification of the SP-like domain using primer 1 and primer 2 as degenerate forward and reverse primers, respectively. The sequences of the primers are shown in Table 1. The PCR was run for 35 cycles of $45 \mathrm{~s}$ at $94{ }^{\circ} \mathrm{C}, 45 \mathrm{~s}$ at $53{ }^{\circ} \mathrm{C}$, and $1 \mathrm{~min}$ at $72{ }^{\circ} \mathrm{C}$. The PCR products were ligated to a $\mathrm{T}$ vector for sequencing.

\subsection{Rapid amplification of the $5^{\prime}$ and $3^{\prime} c D N A$ ends ( $5^{\prime}$ and $3^{\prime}$ RACEs)}

5' RACE was carried out according to the instruction provided by the Invitrogen company. Primer 3 (a gene specific primer, GSP) was used as the reverse primer to synthesize cDNA. Primer 4 (anchor primer, AP) and primer 3 were used to perform the first round of PCR; primer 5 (abridged universal amplification primer, AUAP) and primer 3 were used to perform the second round of PCR.

To amplify the $3^{\prime}$ end of c-SPH, PCR was carried out with primer 6 as the forward primer and primer 7 as the reverse primer. The hemocyte cDNA which was synthesized with oligo $(\mathrm{dT})_{20}$ served as the template. The PCR was run for 35 cycles of $45 \mathrm{sec}$ at $94{ }^{\circ} \mathrm{C}, 45 \mathrm{~s}$ at $62.4^{\circ} \mathrm{C}$, and $1 \mathrm{~min}$ at $72^{\circ} \mathrm{C}$.
Confirmation of a contiguous Pmo c-SPH transcript expressed within hemocytes was demonstrated by RT-PCR amplification of a 1093 bp product using the Pmo c-SPH ORF flanking primers (primer 8 and primer 9) with hemocyte RNA as template.

\subsection{Analysis of the nucleotide and amino acid sequences}

Putative motifs and domains were detected using Motif Scan [18] at the website www.expasy.org. Related sequences were searched with BLASTP 2.2.12 [19] at the National Center for Biotechnology Information (NCBI) and aligned with Clustal X [20]. Phylogenetic and molecular evolutionary analyses according to amino acid sequences of serine protease or serine protease-like domains were conducted with MEGA version 3.1 [21] and a tree was constructed based on the Poisson correction model of neighbor-joining method. The identification of clip domains in SPH sequences was done manually for a cysteine doublet in the N-terminal region of the serine protease-like domain [4].

\subsection{Analysis of the tissue distribution of Pmo c-SPH by nested RT-PCR}

Total RNA was extracted from a variety of shri$\mathrm{mp}$ tissues which included the eyestalk, lymphoid

Table 1

Primers used in this study

\begin{tabular}{|c|c|c|}
\hline Primer & Sequence & Note \\
\hline primer 1 & $5^{\prime}-\mathrm{S}^{506} \mathrm{TKCTGACTGCAGCYCATTG}^{525}-3^{\prime}$ & $\mathrm{S}=\mathrm{G}$ or $\mathrm{C}, \mathrm{K}=\mathrm{G}$ or $\mathrm{T}, \mathrm{Y}=\mathrm{C}$ or $\mathrm{T}$ \\
\hline primer 2 & $5^{\prime}-\mathrm{C}^{1062} \mathrm{CGCAGCCGTAGCCCCARG}^{1044}-3^{\prime}$ & $\mathrm{R}=\mathrm{A}$ or $\mathrm{G}$ \\
\hline primer 3 & $5^{\prime}-\mathrm{C}^{555} \mathrm{GCACGATGAGGTTCCTTTG}^{536}-3^{\prime}$ & \\
\hline primer 4 & 5'-GGCCACGCGTCGACTAGTACGGGIIGGGIIGGGIIG-3' & \\
\hline primer 5 & 5'-GGCCACGCGTCGACTAGTAC-3' & \\
\hline primer 6 & $5^{\prime}-\mathrm{T}^{572}$ TCTCCAAGCCCCAGGACTCGC ${ }^{593}-3^{\prime}$ & \\
\hline primer 7 & 5'-GGCCACGCGTCGACTAGTACTTTTTTTTTTTTTTTTTTT ${ }^{1319}-3^{\prime}$ & \\
\hline primer 8 & $5^{\prime}-\mathrm{C}^{70}$ ATGGACAGGCTGCGGTTGC ${ }^{89}-3^{\prime}$ & \\
\hline primer 9 & $5^{\prime}-\mathrm{G}^{1162}$ TGTCTTCGTTTGTCGCCGG ${ }^{1143}-3^{\prime}$ & \\
\hline primer 10 & $5^{\prime}-\mathrm{A}^{386}$ GCGTAGTCCGCGACATCAC ${ }^{405}-3^{\prime}$ & \\
\hline primer 11 & $5^{\prime}-\mathrm{C}^{449}$ CATCGTCATCCAAGGCAAT ${ }^{430}-3^{\prime}$ & \\
\hline primer 12 & 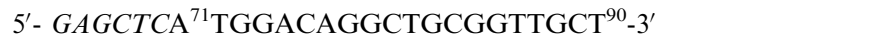 & Italic for $S a c$ I restriction site \\
\hline \multirow[t]{2}{*}{ primer 13} & 5'-TTAATTAATCAGTGGTGGTGGTGGTGGTG & Italic for $P a c$ I restriction site; \\
\hline & $\mathrm{G}^{1135}$ AACCTTACA $\overline{\mathrm{AACTGTC}}{ }^{1119}-3^{\prime}$ & Underlined for $6 \times$ His tag \\
\hline primer 14 & 5'-CCСТTCCСТCGTCTCCAC- $3^{\prime}$ & Beta-tubulin detection \\
\hline primer 15 & 5'-GCCAGTGTACCAGTGAAGGGA-3' & Beta-tubulin gene detection \\
\hline primer 16 & 5'-GCGACGTGGACATCCGTAA-3' & Hemocyte actin gene detection \\
\hline primer 17 & 5'-CGATGCCAGGGTACATGGTAGT-3' & Hemocyte actin gene detection \\
\hline primer 18 & 5'-TGTCGACATCACTGACATGGAA-3' & Prophenoloxidase gene detection \\
\hline primer 19 & 5'-CCGTTGCGATCAATCATGAA-3' & Prophenoloxidase gene detection \\
\hline
\end{tabular}


organ, hepatopancreas, gills, hemocytes, heart, intestine, muscle, and sub-cuticular epithelium using the same method as described above. A 1093-bp fragment of Pmo c-SPH was amplified by RT-PCR using the oligonucleotides primer 8 and primer 9 as forward and reverse primers, respectively. The PCR was run for 25 cycles of $45 \mathrm{~s}$ at $94^{\circ} \mathrm{C}, 45 \mathrm{~s}$ at $58.8^{\circ} \mathrm{C}$, and $75 \mathrm{~s}$ at $72^{\circ} \mathrm{C}$. One microliter of the $1: 1000$ diluted RT-PCR products served as a template to run nested PCR using the oligonucleotides primer 10 and primer 3 as forward and reverse primers, respectively. Twenty-five cycles were run for $45 \mathrm{~s}$ at $94^{\circ} \mathrm{C}, 45 \mathrm{~s}$ at $56.5^{\circ} \mathrm{C}$, and $20 \mathrm{~s}$ at $72^{\circ} \mathrm{C}$. The product was $171 \mathrm{bp}$ in size, as expected, and was further sequenced to confirm the accuracy. Primer 14 (forward) and primer 15 (reverse) were used for detection of endogenous $\beta$-tubulin gene as an internal control. The PCR was run for 35 cycles of $45 \mathrm{~s}$ at $94{ }^{\circ} \mathrm{C}, 45 \mathrm{~s}$ at $58^{\circ} \mathrm{C}$, and $40 \mathrm{~s}$ at $72^{\circ} \mathrm{C}$.

\subsection{Real time PCR quantitation of $c-S P H$ expression}

Ninety-six shrimps were immersed in $1 \mathrm{mg} / \mathrm{mL}$ of yeast $\beta$-glucan (from Saccharomyces cerevisiae, Biotec Mackzymal, Norway) and the controls in sea water for $3 \mathrm{~h}$. Thereafter, all of the shrimps were kept in sea water. Hemolymph was withdrawn from six shrimps at pre immersion and at 30-min, 3-h, 1-day, 3-day, 7-day, 12-day and 16-day post immersion. The hemocyte cDNA, oligonucleotide set, primer 10 and primer 11 (as forward and reverse primers, respectively) and $2 \times$ SYBR Green PCR Master Mix (BioRed, USA) were reacted in PCR to amplify c-SPH cDNA in a $20-\mu \mathrm{L}$ reaction. A hemocyte actin served as an internal control and was detected with primer 16 and primer 17 . Prophenoloxidase cDNA was detected with primer 18 and primer 19 . The thermal cycling parameters were $2 \mathrm{~min}$ at $50^{\circ} \mathrm{C}, 10 \mathrm{~min}$ at $95^{\circ} \mathrm{C}$, and 40 cycles run for $15 \mathrm{~s}$ at $95^{\circ} \mathrm{C}$ and $1 \mathrm{~min}$ at $60^{\circ} \mathrm{C}$. The Applied Biosystem Prism 7000 Sequence Detector System (Foster City, CA) measured fluorescent emissions continuously during the PCR amplification. The point representing the detection threshold of an increase in the fluorescent signal associated with an exponential growth of the PCR product for the detector is defined as the cycle threshold $\left(C_{T}\right)$. Relative expression ratio was defined as (c-SPH expression level of sea water or glucan immersed shrimp)/(c-SPH expression level of pre-immersed shrimp). Relative expression ratio of c-SPH of sea water and glucan immersed shrimp was compared and analyzed with Student's $t$-test. The specificity of real time PCR products was confirmed by melting curve analysis. The possibility of any genome contamination was excluded because of an intron located in the PCR fragment (data not shown).

\subsection{Biosynthesis of recombinant c-SPH}

The oligonucleotides, primer 8 and primer 9 , were used as forward and reverse primers, respectively, to amplify c-SPH ORF in PCR. Thirty cycles were run for $45 \mathrm{sec}$ at $94{ }^{\circ} \mathrm{C}, 45 \mathrm{~s}$ at $58^{\circ} \mathrm{C}$ and $90 \mathrm{~s}$ at $72{ }^{\circ} \mathrm{C}$. The PCR product was ligated to vector pGEM-T Easy (Promega) and transformed to Escherichia coli DH-5 $\alpha$.

To clone c-SPH cDNA into the transfer vector, the c-SPH ORF-transformed DH-5 $\alpha$ cells were used as a template, and the primers flanking restriction sites (in italics) were used for PCR mutagenesis. The forward primer (primer 12) contained a Sac I restriction site and the reverse primer (primer 13) a Pac I restriction site and a $6 \times$ His tag. The c-SPH cDNA fragment that contained the translation start codon ATG, the entire coding region of the c-SPH (including the signal sequence), the $6 \times$ His tag codon, the stop codon, and the Sac I and Pac I restriction sites at the $5^{\prime}$ and $3^{\prime}$ ends of the insert was cloned into the pABhRpX transfer vector and introduced into E. coli $\mathrm{DH}-5 \alpha$ cells. The pABhRpX transfer vector had an HSP70 promoter to express a DsRed fluorescent marker and a polyhedrin promoter to express the insert gene. The orientation and sequence of the c-SPH insert was verified by sequencing. After cotransfection of the pABhRpXc-SPH plasmid and BaculoGold Linearized Baculovirus DNA (Pharmingen) into Spodoptera frugiperda $S f 21$ cells (a gift from Dr. Y.C. Chao) with $10 \mu \mathrm{g} / \mathrm{mL}$ lipofectin (Life Technologies, USA), $S f 21$ cells were cultured at $26^{\circ} \mathrm{C}$ in TNM-FH insect cell medium (Grace's insect cell culture medium (Gibco), $3 \mathrm{~g} / \mathrm{L}$ Bacto $^{\mathrm{TM}}$ TC yeastolate (BD), $3 \mathrm{~g} / \mathrm{L}$ lactalbumin hydrolysate (Gibco), and $\mathrm{NaHCO}_{3} ; \mathrm{pH}$ 6.3; $390 \mathrm{mOsm} / \mathrm{kg}$ ) containing $8 \%$ heat-inactivated fetal bovine serum for propagating the recombinant Autographa californica multiple nuclearpolyhedrovirus (AcMNPV). We obtained viable recombinant baculovirus that showed fluorescence of DsRed according to the manufacturer's instruction (Pharmingen).

For recombinant protein production, $S f 21$ monolayers cultured in T-flask were infected by 
recombinant virus at a multiplicity of infection between 3 and 10 . Infected $S f 21$ cells were harvested at 3-day post-infection and then vortexed in lysis buffer $\left(50 \mathrm{mM} \mathrm{NaH} \mathrm{NO}_{4}, 300 \mathrm{mM} \mathrm{NaCl}, 32 \mathrm{mM}\right.$ dithiothreitol (DTT), and $8 \mathrm{M}$ urea; $\mathrm{pH} 8.0$ ). The cell lysate was centrifuged at $12,000 \mathrm{~g}$ for $10 \mathrm{~min}$ at $4{ }^{\circ} \mathrm{C}$ and the clear supernatant was subjected to an Ni-NTA column (Qiagen, Germany), and flowed continuously with washing solution $\left(50 \mathrm{mM} \mathrm{NaH}_{2-}\right.$ $\mathrm{PO}_{4}, 300 \mathrm{mM} \mathrm{NaCl}, 32 \mathrm{mM}$ DTT, $8 \mathrm{M}$ urea, and $20 \mathrm{mM}$ imidazole; $\mathrm{pH}$ 8.0) until the $\mathrm{OD}_{280 \mathrm{~nm}}$ of the flow-through was lower than 0.1 . The recombinant protein was then eluted using the washing solution supplemented with imidazole to $250 \mathrm{mM}$, and dialyzed against PBS at $4{ }^{\circ} \mathrm{C}$ overnight. The protein concentration was determined using the Bradford method [22] with bovine serum albumin (BSA) as a standard.

\subsection{SDS-PAGE and immunoblotting}

The recombinant protein samples were boiled for $10 \mathrm{~min}$ in sample buffer $(125 \mathrm{mM}$ Tris, $2 \mathrm{mM}$ EDTA $\cdot 2 \mathrm{Na}, 2 \% \mathrm{SDS}$, and $5 \% \beta$-mercaptoethanol) and subjected to electrophoresis in $12.5 \%$ SDSpolyacrylamide gels. One of the gels was stained by silver stain; the other gel was transferred to a PVDF membrane (Millipore, USA) for immunoblotting at $400 \mathrm{~mA}$ for $90 \mathrm{~min}$ in transfer buffer $(25 \mathrm{mM}$ Tris, $192 \mathrm{mM}$ glycine, and 10\% methanol). The membrane was then immersed in $6 \mathrm{M}$ urea in PBST $(0.05 \%$ Tween 20 in PBS) overnight and incubated for $1 \mathrm{~h}$ in blocking buffer $(0.25 \%$ gelatin, $0.15 \mathrm{M}$ $\mathrm{NaCl}, 5 \mathrm{mM}$ EDTA, $50 \mathrm{mM}$ Tris, and $0.05 \%$ Tween 20). After three washes in PBST, the membrane was incubated for $1 \mathrm{~h}$ in PBS containing mouse anti$4 \times$ His tag antibody (1:1000 dilution, Qiagen), washed three times for $10 \mathrm{~min}$ each in PBST, incubated in alkaline phosphatase-conjugated rabbit anti-mouse IgG (1:2000 dilution, Abcam, USA) for $1 \mathrm{hr}$ and washed four times for $10 \mathrm{~min}$ each in PBST and once for $10 \mathrm{~min}$ in TBS $(100 \mathrm{mM}$ Tris, $100 \mathrm{mM} \mathrm{NaCl}$, and $50 \mathrm{mM} \mathrm{MgCl}_{2} ; \mathrm{pH}$ 9.5). After which the color development was allowed in $15 \mathrm{~mL}$ of TBS containing $60 \mu \mathrm{L}$ of NBT/BCIP (Roche).

\subsection{Cell adhesion assay}

The cell adhesion assay mainly followed that in Current Protocols in Cell Biology Online, with a slight modification (2004, John Wiley \& Sons, Inc., www3.interscience.wiley.com). Reactions were car- ried out at room temperature if not otherwise specified. Briefly, $100 \mu \mathrm{L}$ of c-SPH recombinant protein $(0,0.25,0.83,1.66,2.5$, or $25 \mu \mathrm{g} / \mathrm{mL})$ was added into each well of an ELISA plate and incubated at $4{ }^{\circ} \mathrm{C}$ overnight. A blocking solution of 5\% BSA in PBS was then added and kept for $1 \mathrm{~h}$. Hemocyte suspension was prepared in modified L15 medium (L-15, additional $\mathrm{NaCl} 5 \mathrm{~g} / \mathrm{L}$, and glucose $1 \mathrm{~g} / \mathrm{L} ; 780 \pm 15 \mathrm{mOsm} / \mathrm{kg}$ ) and $98 \%$ cell viability was determined via a vital exclusion stain of trypan blue $(0.4 \%$, Sigma $)$. One hundred microliter of hemocyte suspension $\left(10^{6}\right.$ cells $\left./ \mathrm{mL}\right)$ was added into each well, incubated for $20 \mathrm{~min}$, washed, fixed in 5\% glutaraldehyde for $20 \mathrm{~min}$, washed, and stained with crystal violet solution $(0.1 \%$ in $200 \mathrm{mM}$ 2-( $N$-morpholino)ethanesulfonic acid; $\mathrm{pH}$ 6.0) for $1 \mathrm{~h}$. After washing with distilled water three times, each well had $100 \mu \mathrm{L}$ acetic acid $(10 \%, \mathrm{v} / \mathrm{v})$ added into it to dissolve the crystal violet. After incubation for $5 \mathrm{~min}$, the percentage of attached cells was assessed by measuring the $\mathrm{OD}_{590 \mathrm{~nm}}$ with a 96 -well Microplate Reader (Tekon, Taiwan). To convert the OD value to an adhesion rate, we constructed a calibration curve by adding $100 \mu \mathrm{L}$ of $10^{6}, 8 \times 10^{5}$, $6 \times 10^{5}, 4 \times 10^{5}$, or $2 \times 10^{5}$ cells $/ \mathrm{mL}$ of hemocyte suspension into each well without c-SPH coating or blocking. The OD value of $10^{6}$ cells $/ \mathrm{mL}$ of hemocyte suspension in wells without coating or blocking was calibrated as $100 \%$ adhesion. The data were statistically analyzed using a paired Student's $t$-test.

\section{Results}

\subsection{Cloning and sequence analysis of the $c-S P H$ molecule in P. monodon}

The domain organization and nucleotide and deduced amino acid sequences of the $P$. monodon cSPH molecule (Pmo c-SPH) are shown in Fig. 1. The full length cDNA of Pmo c-SPH contains $1337 \mathrm{bp}$, including an open reading frame of $1068 \mathrm{bp}$, a $5^{\prime}$ untranslated region of $70 \mathrm{bp}$, and a $3^{\prime}$ untranslated region of $199 \mathrm{bp}$. The deduced protein sequence contains 355 amino acid residues with a putative secretory signal peptide cleavage site between $\mathrm{Gly}^{21}$ and $\mathrm{Gln}^{22}$. The putative whole protein molecular weight is approximately $37.9 \mathrm{kDa}$ and its putative $\mathrm{pI}$ is 7.91 , whereas the putative mature protein molecular weight is approximately $35.8 \mathrm{kDa}$ and its putative $\mathrm{pI}$ is 7.61 . Structurally, Pmo c-SPH has the characteristic 


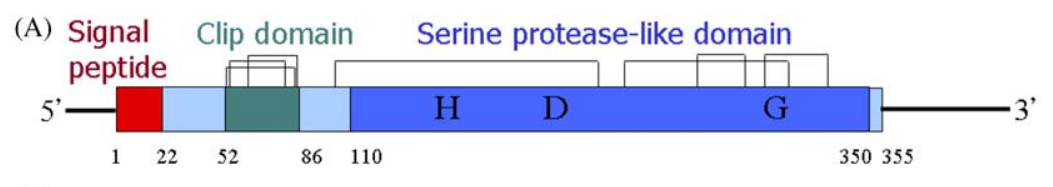

(B)

\section{1}

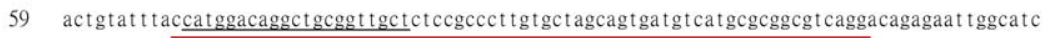

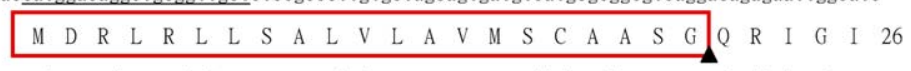

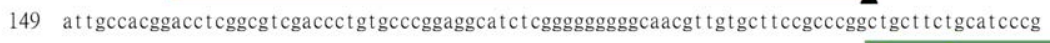

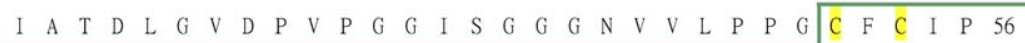

239 gtcaaccaagt $t$ tgeccet $t$ cagaact gaagt t cgagt tggat $t$ tagaccgg tgg tggagcgt tgcccaga tcagaaggaa tgct tgetct

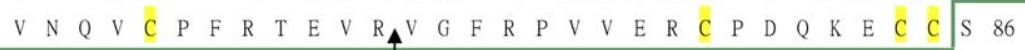

329 tccatcggtgcgactacgctccegccgacat cgeccetggggt cctgtggtagacagagcgtagtccgegacatcacccacggcccagct

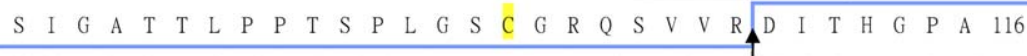

419 t tgttcggtgaat tgect tggatgacgatggtgct caacgggagagg agctacg tggcaggt ggcgccetcatctccagcgagtgggtc $\begin{array}{lllllllllllllllllllllllllllllll}\mathrm{L} & \mathrm{F} & \mathrm{G} & \mathrm{E} & \mathrm{L} & \mathrm{P} & \mathbf{W} & \mathrm{M} & \mathrm{T} & \mathrm{M} & \mathrm{V} & \mathrm{L} & \mathrm{N} & \mathrm{G} & \mathrm{R} & \mathrm{G} & \mathrm{S} & \mathrm{Y} & \mathrm{V} & \mathrm{A} & \mathrm{G} & \mathrm{G} & \mathrm{A} & \mathrm{L} & \mathrm{I} & \mathrm{S} & \mathrm{S} & \mathrm{E} & \text { W } & \mathrm{V} & 146\end{array}$

509 ctgacagcagctcaccggatccgaaatcaaaggaacctcatcgtgcgtctgggcgagct ggact tctccaagccccaggactcgccccag $\begin{array}{llllllllllllllllllllllllllllllll}\text { L } & T & A & A & H & R & I & R & N & Q & R & N & L & I & V & R & L & G & E & L & D & F & S & K & P & Q & D & S & P & Q & 176\end{array}$ 599 tacacccaccgagacg tgccgat cgacaacat cat cg tgcacccgcagt tcaact cccagaccet cgccaacgacgt cgct ct cct tgcac

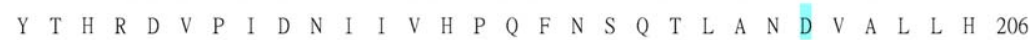

689 ctctccegccetgtctacactgcaat tgctccgcacat cggcgccgtctgct tgcct tctcagggccagatct tccagggacggaaatgc

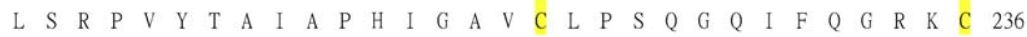

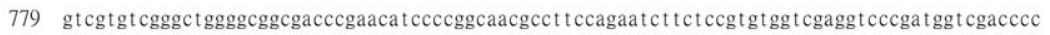

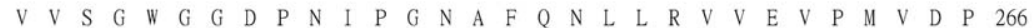

869 t tcgectgccagcagcgectcggaaccgcccgect cggagccaact tcaccct cgaccaaacg tcct tcgt ctgcgetgggggagt cgaa

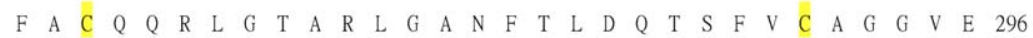

959 gggaacgacgcgtgcaccggcgat ggcgggtctcctct tgtgtgtctgaacgataacagaagctggacat tggt tggectggt tgcctgg

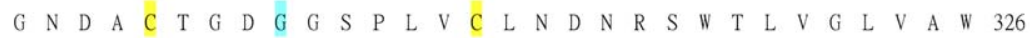

1049 ggtctcggctgcgcccagagggaagt t ccagg tgt ctatgt caacg t tgcct cg tat accaact t cat ccgacagt t tgtaaggt tc tga

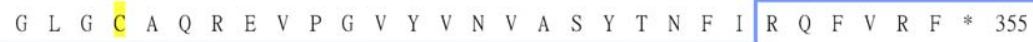

1139 tacaccggcgacaaacgaagacact $t$ tgg tggatgt tacaaagaaat $t$ taagct gagaact $t$ t t cg tacaaggagagaaca tccat $t$ t $t$ t a 1229 tgatccetgtgat at tacctcact tcatgcaaatatgaat tat tat tat tat tat tat $t$ t $t$ tactgeggtgaagaaacctgagaaacat 1319 aaaaaaaaaaaaaaaaaa

Fig. 1. Domain organization (A) and nucleotide and deduced amino acid sequences (B) of Penaeus monodon c-SPH. (A) Shrimp c-SPH is composed of a signal peptide (red), one clip domain (green), one serine protease-like domain (dark blue), and linker sequences (light blue). The numbers representing the first amino acid residues of each region are labeled at the bottom of the expression. Disulfide bonds are shown as solid line linkages and the replacement catalytic triad is marked as H, D, and G. (B). The numbers representing the nucleotide sequence are labeled on the left side; those representing the amino acid sequence are labeled on the right side. Primers used in the study are underlined. The black triangle indicates the putative cleavage site for the signal peptide. The arrows indicate the putative activation cleavage sites. The catalytic triad of the SP-like domain, including a replacement Gly ${ }^{305}$ instead of Ser, is highlighted in blue. The potential disulfide bond-forming cysteines are marked in yellow.

features of the clip domain family of serine protease homologs: one amino-terminal disulfide knotted clip domain and one SP-like domain in the carboxylterminus (Fig. 1A). One amino acid replacement occurs in the sequence of the SP-like domain, namely glycine instead of serine in the catalytic triad (His ${ }^{151}, \mathrm{Asp}^{201}, \mathrm{Ser} \rightarrow \mathrm{Gly}^{305}$ ). There are two putative proteolytic activation cleavage sites: one in the clip domain (between $\mathrm{Arg}^{68}$ and $\mathrm{Val}^{69}$; Fig. 1B) and the other at the beginning of the SP-like domain (between $\mathrm{Arg}^{109}$ and Asp ${ }^{110}$; Fig. 1B). A putative inter-domain disulfide bond $\left(\mathrm{Cys}^{102}-\mathrm{Cys}^{223}\right)$ links the clip domain and the SP-like domain after activation. There are also six predicted disulfide bonds, three in the clip domain and three in the SPlike domain, as indicated in Fig. 1A. 


\subsection{Comparison of c-SPH molecules in arthropods}

By using NCBI BLASTP with $E$-values less than $10^{-32}, 66$ sequences were retrieved from GenBank as of December 2005. The sequences without basic characterization were removed first. Then 17 sequences containing an $\mathrm{N}$ terminal clip domain(s) with six conserved cysteine residues and a $\mathrm{C}$ terminal SP-like domain with the conversion of Ser into Gly in the catalytic triad were kept for further analysis. Many of these c-SPH molecules have been annotated as immune-related proteins and most of them have a size ranging from 350 to 450 amino acid residues with a single clip domain.

Multiple sequence alignment analyses were performed to compare the clip domains (Fig. 2A) and serine protease-like domains (Fig. 2B) of single clip domain SPH molecules. In spite of the low similarity in those clip domains of 15 sequences, there are six cysteine residues corresponding to the three disulfide bonds conserved in the clip domain (Cys1-Cys5, Cys2-Cys4, Cys3-Cys6; Fig. 2A). In the SP-like domains, the conserved residues are concentrated in sequences close to the catalytic triad $\left(\mathrm{His}^{151}, \mathrm{Asp}^{201}, \mathrm{Gly}^{305}\right.$ ) and to the amino acid residues forming the substrate specificity pocket in catalytically active serine proteases $\left(\mathrm{Asp}^{299}\right.$, $\mathrm{Gly}^{327}$,
Gly $^{337}$ ), for instance, VLTAA프, DIAL, GDGGS/

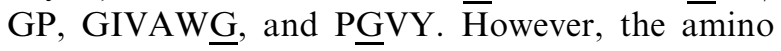
acid sequence of the four signatures featured SP-like domain of c-SPH seems not so conserved. Shrimp c-SPH is most similar to the low molecular mass masquerade-like protein of crayfish, but less similar to c-SPHs in Chelicerata and Insecta (Fig. 3). Multiclip domain SPHs, such as crayfish mas-like and fruit fly mas, are apparently not similar to singleclip domain SPHs. In our phylogenetic tree, we also included four enzymatically active single clip domain serine proteases, horseshoe crab factor B (accession number BAA03528) and proclotting enzyme (AAA30094), fruit fly easter precursor (P13582), and tobacco hornworm proPO activating enzyme precursor (AAC64004). Catalytically active clip domain serine proteases are far from their catalytically inactive homologs.

\subsection{Expression of the c-SPH molecule in shrimp}

Nested RT-PCR showed that the mRNA encoding c-SPH is detected most in the hemocyte, less in the hemocyte abundant tissues such as lymphoid organ, hepatopancreas, gill and heart, and none in all other tested organs such as eye, eye stalk, intestine, muscle and sub-cuticular epithelium

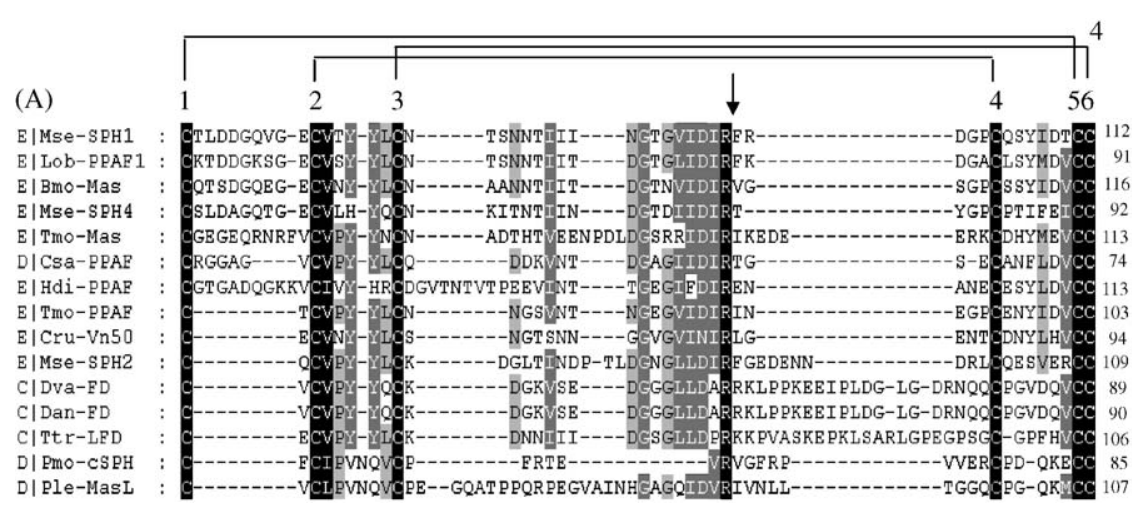

Fig. 2. Multiple alignments of clip domains (A) and SP-like domains (B) of single clip domain SPHs. The amino acid sequence of PmocSPH (AY600627) was aligned with those of Mse-SPH1 (AAM69352), Lob-PPAF1 (AAV91458), Bmo-Mas (AAN77090), Mse-SPH4 (AAV91027), Tmo-Mas (BAC15605), Csa-PPAF (AAS60227), Hdi-PPAF (CAC12665), Tmo-PPAF (CAC12696), Cru-Vn50 (AAP49428), Mse-SPH2 (AAM69353), Dva-FD (AAN78224), Dan-FD (AAO12856), Ttr-LFD (BAA13312), and Ple-MasL (AAX55746) using the Clustal X program. Highly, mediate, and low conserved amino acid residues are enclosed in black, dark gray, and light gray boxes, respectively. (A) The six conserved cysteines in the clip domain are numbered and the linkages were demonstrated as Cys1-Cys5, Cys2-Cys4, and Cys3-Cys6 in the Tachypleus tridentatus proclotting enzyme. The putative proteolytic activation cleavage site according to $H d i$-PPAF is shown by an arrow. Gaps (-) were introduced to maximize the alignment of the clip domain cysteines. (B) The putative proteolytic activation cleavage site is shown by an arrow; the SP catalytic triad is indicated by black dots; the amino acid residues forming the substrate specificity pocket in catalytically active serine proteases are indicated by black squares; the putative inter-domain disulfide bond is indicated by a double line; the disulfide linkages in the SP-like domain are shown by solid lines, the four signature regions in c-SPH are underlined; and the typical disulfide bond in trypsin which is absent in some c-SPH molecules is shown by a dotted line. 
(B)

E|Mse-SPH1
E |Mse-SPH4
E | Bmo-Mas
E | Lob-PPAF 1
E Tmo-PPAF
E |Cru-Vn50
E | Hdi-PPAF
E Tmo-Mas
E |Mse-SPH2
D|Csa-PPAF
C| Dva-FD
C| Dan-FD
C| Ttr-LED
D| Pmo-CSPH
D| Ple-MasL

E | Mse-SPH1

E|Mse-SPH 4

E | Bmo-Mas

E TMO-PPAE

E Cru-Vn50

E | Hdi-PPAE

E| Tmo-Mas

E|Mse-SPH2

D|Csa-PPAF

C| Dva-ED

$C \mid$ Dan-FD

C|Ttr-LED

D) Pmo-CSPH

D| Ple-MasL
E | LOb-PPAF 1

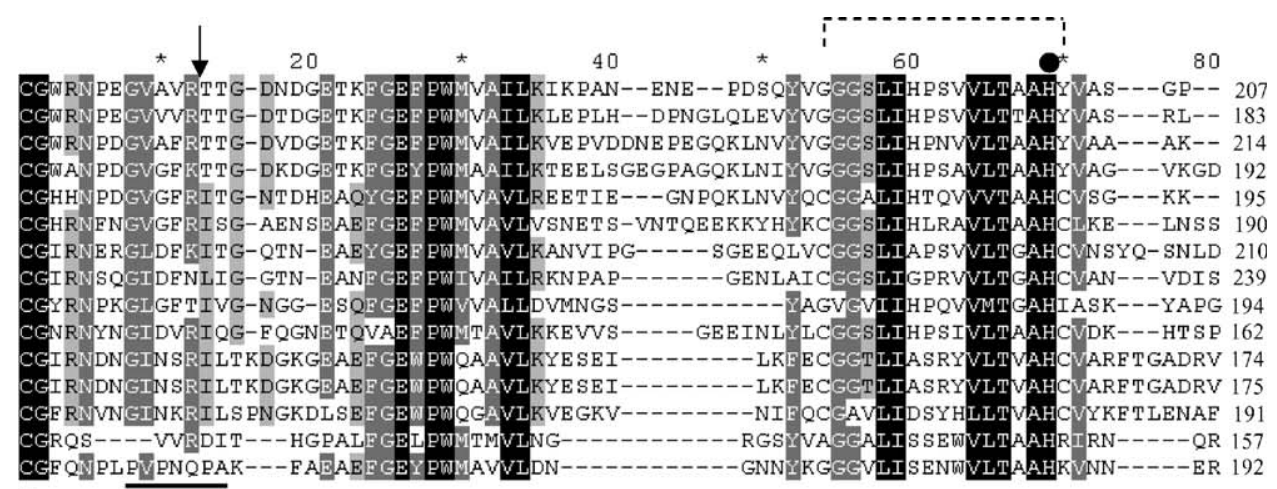
II

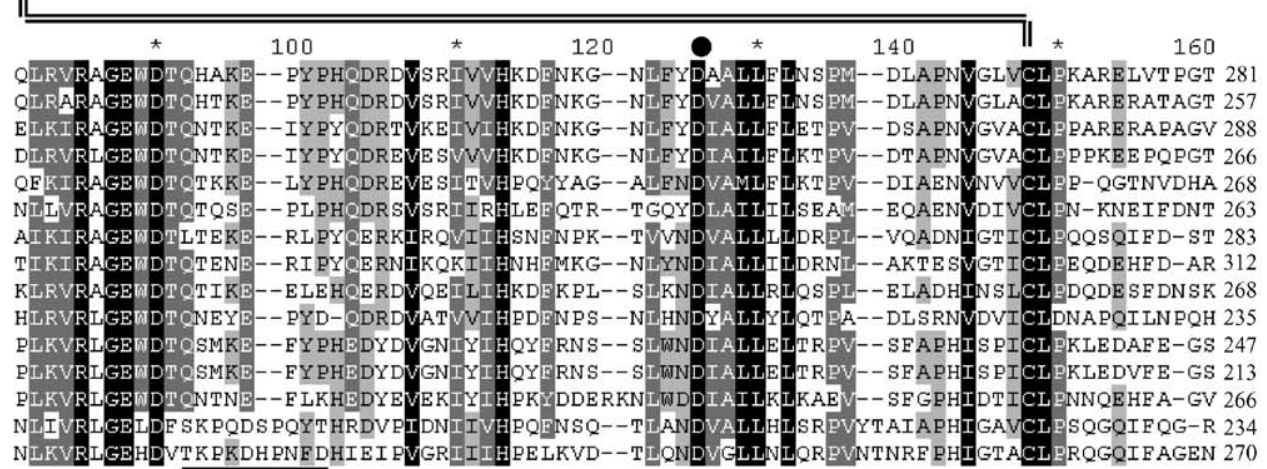

E|Mse-sPH 1

E | Mse-SPH 4

E| Bmo-Mas

E | LOb-PPAE ]

E TMO-PPAF

E) Cru-Vn50

E Hdi-PPAE

E| Tmo-Mas

E| Mse-SPH2

D|Csa-PPA.

C| Dva-ED

C|Dan-ED

C) Ttr-LED

D) Pmo-CSPH

D| Ple-MasL

E|Mse-SPH1

E| Mse-s PH 4

E| Bmo-Mas

E | Lob-PPAF

E | TMO-PPAE

E Cru-Vn50

E| Hdi-PPAF

E| Tmo-Mas

E|Mse-s PH2

D) Csa-PPAE

C|Dva-ED

C| Dan-FD

C|Ttr-LED

D) PMo-CSPH

D) Ple-MasL
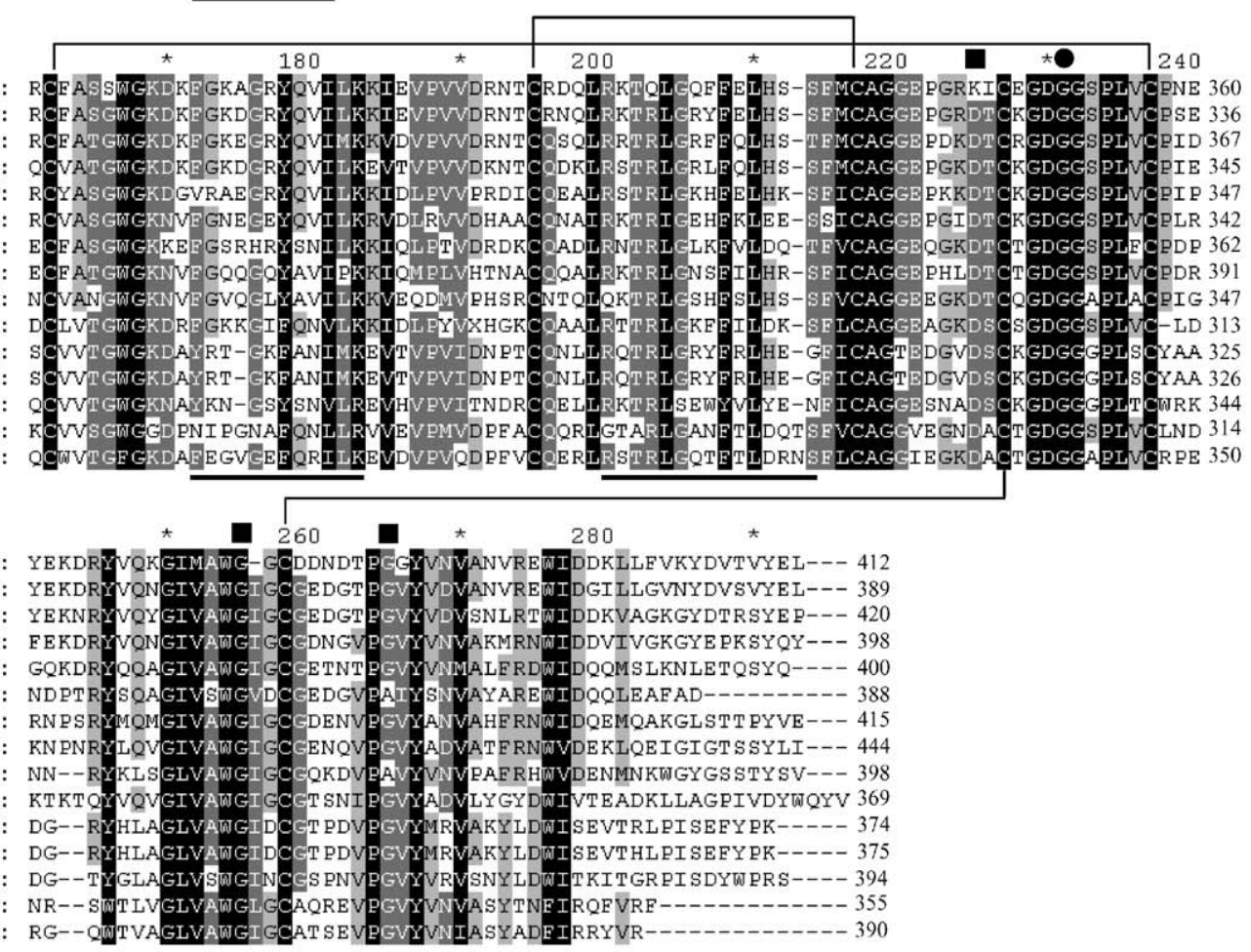

Fig. 2. (Continued)
(Fig. 4). Endogenous $\beta$-tubulin gene was used as an internal control and was detected in all tested organs but in eye and eye stalk. When shrimps were immersed in sea water, there is no significant difference in c-SPH expression between seawater and glucan immersion until the 12-day post 


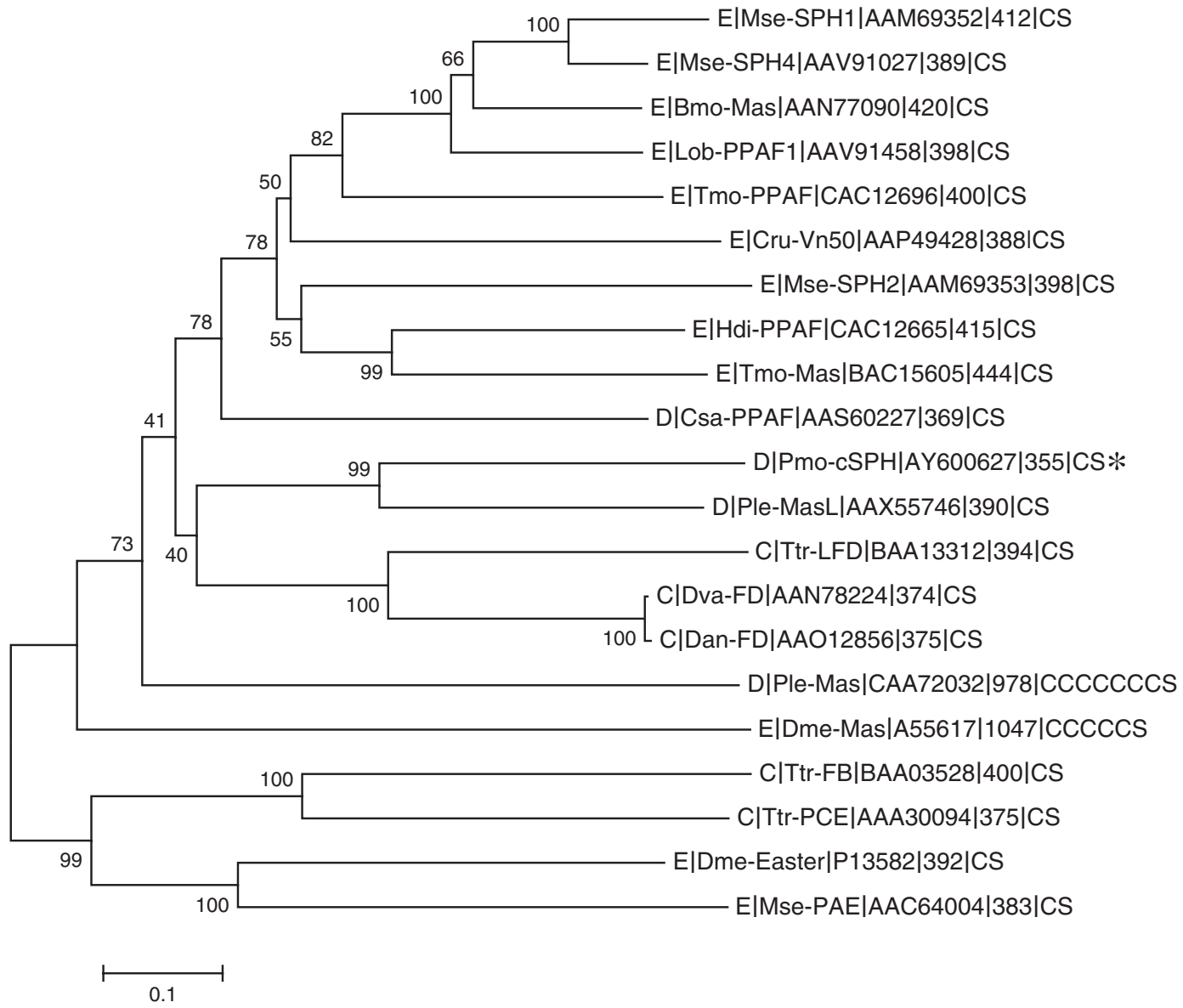

Fig. 3. Phylogenetic analysis of c-SPHs in arthropods. A comparison of 15 single clip domain serine protease homologs (in Fig. 2), 2 multiple clip domain SPHs (Ple-Mas and Dme-Mas), and 4 enzymatically active single clip domain serine proteases (Ttr-FB, Ttr-PCE, Dme-Easter, and Mse-PAE) was constructed according to Poisson correction model of a neighbor-joining analysis of the amino acid or deduced amino acid sequence of their serine protease-like domains. All the sequences in the tree are labeled as [organism type| protein ID| GenBank accession number| sequence length| domain organization] in this information-rich tree. Organism type of $\mathrm{E}$ means Endopterygota, D means Decapoda, and C means Chelicerata. Domain organization of C means clip domain, and S means SP or SP-like domain. The scale bar indicates 0.1 substitution per site. The number at each branch represents the bootstrap (1000 replications) ratio.

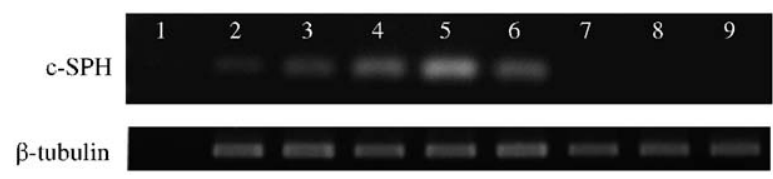

Fig. 4. Tissue distribution of Pmo c-SPH mRNA. Pmo-cSPH expression was detected with nested RT-PCR in various tissues. Lane 1: eye and eye stalk, 2: lymphoid organ, 3: hepatopancreas, 4: gill, 5: hemocyte, 6: heart, 7: intestine, 8: muscle, 9: subcuticular epithelium. Beta-tubulin gene was used as an internal control. Shrimp c-SPH mRNA was detected most in the hemocyte, less in the lymphoid organ, hepatopancreas, gill and heart, but none in the eye, eye stalk, intestine, muscle and subcuticular epithelium. immersion. The expression of c-SPHs in the hemocytes of glucan-immersed shrimp was upregulated at 12-day post immersion. This enhancement effect was approximately twice that demonstrated in the control group (Fig. 5). On the other hand, proPO gene expression increased about 2.8fold at 0.5 -h post immersion.

\subsection{Characterization of the recombinant protein}

The concentration of purified and dialyzed recombinant protein was determined to be $25 \mu \mathrm{g} / \mathrm{mL}$. 


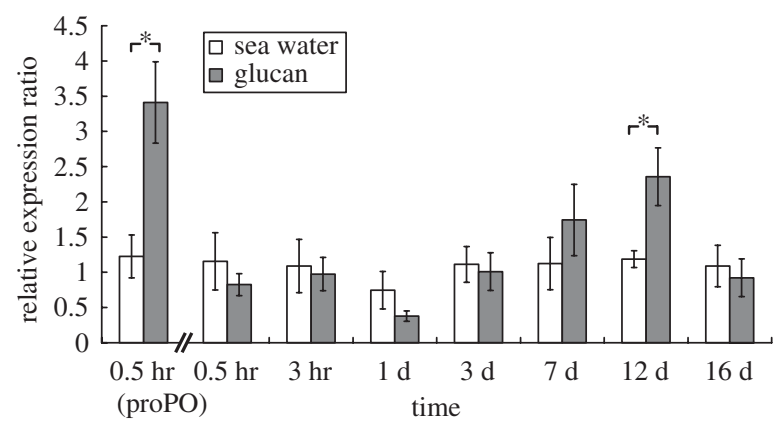

Fig. 5. Expression of hemocyte c-SPH mRNA after immersing the shrimp in $\beta$-glucan suspension $(1 \mathrm{mg} / \mathrm{mL})$ or sea water for 3 hours. The relative expression was measured using hemocyte actin as an internal control. Real-time PCR was used to quantify mRNA. Expression of prophenoloxidase gene up-regulated at $0.5 \mathrm{~h}$ was viewed as an acute-phase response. The results are shown as means \pm standard errors $(n=6)$. A significant difference in c-SPH expression ( $\mathrm{t}$ test, $p<0.05$ ) "** "between glucan and sea water treatments was detected at 12-day post-immersion. No significant difference was found between sea water-treated groups at any two time points.
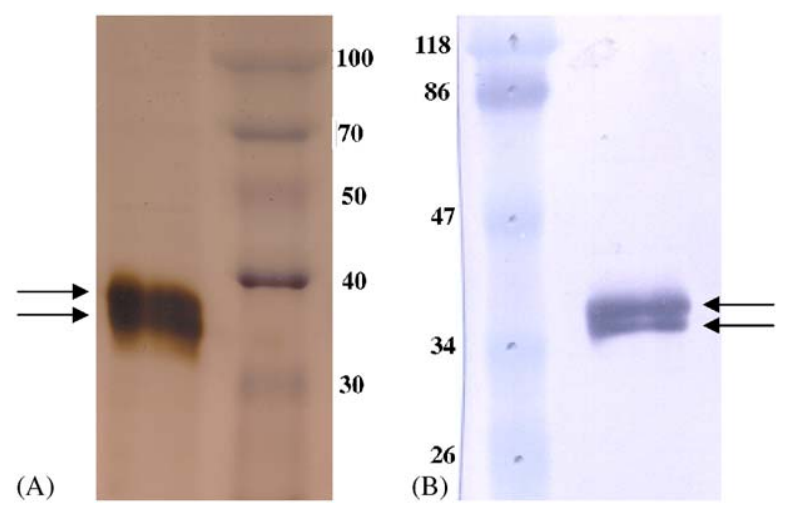

Fig. 6. SDS-PAGE (A) and immunoblotting (B) analysis of recombinant Pmo c-SPH. SDS-PAGE of recombinant protein eluted from Ni-NTA agarose implies two proteins of MW 36 and $38 \mathrm{kDa}$ in the left lane (arrows). The MW of the lower band corresponds to the protein produced by cleavage of the signal peptide. That of the higher band may be the naïve protein with the signal peptide or the mature protein with glycosylated modification. Molecular mass markers are shown in $\mathrm{kDa}$ on the right lane. (B) Immunoblotting of recombinant protein with anti $4 \times$ His tag antibody shows two bands of 36 and $38 \mathrm{kDa}$ in the right lane (arrows). Protein molecular mass markers are shown in $\mathrm{kDa}$ on the left lane.

Two bands, $38 \mathrm{kDa}$ and $36 \mathrm{kDa}$ in molecular weight, were shown on polyacrylamide gel. The $36 \mathrm{kDa}$ band corresponds approximately to the mature c-SPH proteins without a signal peptide (Fig. 6A). The $38 \mathrm{kDa}$ band may be due to the unleavened signal peptide or glycosylation.

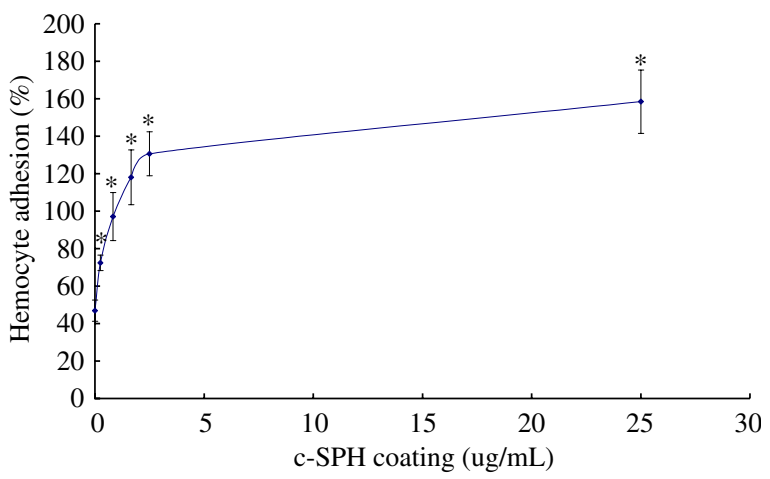

Fig. 7. Hemocyte adhesion assay. The ELISA plates were coated with c-SPH recombinant protein in different concentration $(0$, $0.25,0.83,1.66,2.5$, and $25 \mu \mathrm{g} / \mathrm{mL}$ ) respectively. Then these plates were blocked with $5 \%$ BSA. Hemocyte adhesion in wells without coating or blocking was calibrated as $100 \%$ adhesion. The results are shown as means \pm standard errors $(n=4)$. There are significant differences in hemocyte adhesion "** "(paired $t$-test, $p<0.05$ ) between treatments with coating and without coating. The effect of c-SPH on hemocyte adhesion is dose-dependent.

These were further characterized by immunoblotting (Fig. 6B).

\subsection{Cell adhesion activity of c-SPH}

The recombinant c-SPH was shown to increase the hemocyte adhesion significantly in a dosedependent manner (Fig. 7). The calibration curve of adhesive hemocyte rate versus OD value was OD value $=0.31$ adhesion rate +0.0191 , and correlation coefficient $r^{2}=0.9811$. The hemocyte adhesion was enhanced by the recombinant c-SPH up to 3.4-fold at a concentration of $25 \mu \mathrm{g} / \mathrm{mL}$. However, few hemocytes were found to be adhesive when they were suspended in citrate-containing anticoagulant without supplemented calcium (data not shown). This phenomenon implies that the hemocytes adhesion effect of c-SPH protein is calcium-dependent.

\section{Discussion}

\subsection{Sequence analysis of shrimp c-SPH molecule}

Although the replacement catalytic triad pattern-His, Asp, Gly- has also been found in Mpnprov and LOC443716 proteins of amphibians (Xenopus sp., accession numbers AAH89702 and AAH74480) [23], the clip domain is unique to arthropods [4]. Most c-SPHs, such as Pmo c-SPH, contain one clip domain and their sizes range from 
350 to 450 amino acid residues. The overall sequence similarity between different clip domains is low, but the six Cys residues are strictly conserved. Although SPHs do not perform enzymatic activity, the sequences close to the amino acid residues forming the substrate specificity pocket in catalytically active serine protease are well conserved. This implies that the substrate specificity pocket in the SPHs still plays a role such as protein-protein interaction. The Pmo c-SPH is categorized as a member of the group 1a of the clip-domain family of serine proteases (c-SPs) according to Ross et al. [24]; its characteristics include the presence of shorter sequence (8-16 amino acid residues) between Cys 3 and Cys 4 and of Lys or Arg residue before the putative activation cutting site, and the absence of group 2 c-SPsspecific insertion between $\mathrm{His}$ and Asp of the catalytic triad. The insertion includes two Cys residues which form a disulfide bond and result in a loop structure which is potentially involved in the regulation of the prophenoloxidase system. Both the structures of clip domain and antimicrobial defensin contain three disulfide bonds, but the structure of clip domain of Hdi-PPAF-II, a member of group 2, has been demonstrated distinct from that of the defensin. On the other hand, the sequences of group 1 c-SPs clip domains are similar to bovine and $T$. tridentatus defensins. However, neither the shrimp c-SPH nor the chemically synthesized clip domain of the shrimp c-SPH shows anti-E. coli activity in the lysis assay assessed with a spectrophotometer (data not shown). Further study is needed to determine whether shrimp c-SPH has an antimicrobial activity against other microbes or requires a cleavage activation at the putative cleavage site either between $\mathrm{Arg}^{68}$ and $\mathrm{Val}^{69}$ in the clip domain or between $\mathrm{Arg}^{109}$ and $\mathrm{Asp}^{110}$ at the beginning of the SP-like domain.

\subsection{Comparison of c-SPH molecules in arthropods}

In the phylogenetic tree, the amino acid sequences used to construct the tree were the regions of the relatively conserved SP or SP-like domain rather than the whole molecule containing the highly variable clip domain. Four enzymatically active single clip domain serine proteases, Ttr-FB, TtrPCE, Dme-easter and Mse-PAE, were analyzed; it was revealed that they are different from catalytically inactive SPHs and can be viewed as the outgroups. Although we categorized one molecule as a serine protease "homolog" by the Gly substitution for Ser, this result implies that there must be significant difference between c-SP and c-SPH molecules and that divergence may be an early event between the two groups in the evolution of arthropods. There may be some hints in the recent study by Piao et al., notably the presence of calcium-binding loop, four signature regions in SP-like domain, and alpha helix at $\mathrm{N}$ terminus which are able to discriminate c-SP from c-SPH. Although the four signatures in the SP-like domain seem not so conserved in the shrimp c-SPH, the hepta-coordinated functional groups of the calcium binding loop is well conserved (the carboxylates of Glu $^{165}$ and Asp ${ }^{173}$, the carbonyl oxygens of Asp ${ }^{167}$ and Lys ${ }^{170}$, and two water [5]). Besides the divergence of c-SP and c-SPH, the SPH molecules containing multiple clip domains, such as fruit fly $D$. melanogaster masquerade and signal crayfish $P$. leniusculus masquerade-like molecule, may diverge from the SPH molecules containing a single clip domain. Hence, the present molecule was given the name Pmo c-SPH.

\subsection{Expression profile of shrimp c-SPH}

Shrimp c-SPH expression is detected most in the hemocytes. In the other hemocyte-rich tissues such as gills, heart, hepatopancreas, and lymphoid organ, the minor signals may be the result of hemocyte cDNA contamination. Absence of detectable bands in the eye and eye stalk may be due to the PCR inhibitors which are present in the eye stalk and always cause the amplification reaction to fail [25]. The hemocytes become activated on receiving pathogen signals and are then involved in defense against the invading microorganism. Glucan has been demonstrated as an effective immunostimulant for shrimp in enhancing non-specific disease resistance [26]. In glucan-immersed shrimp, the c-SPH expression was mildly regulated. The late phase induction (12-day post immersion) is different from an acute phase induction of shrimp proPO gene and seems to be a unique induction pattern. This pattern also implies that the inductive effect may not be elicited directly by the glucan signal transduction pathway. Another signal involving the exhaustion of c-SPH may trigger the compensation feedback. Two forms of recombinant protein exist in $S f 21$ cells with molecular weights of 36 and $38 \mathrm{kDa}$. This suggests a differential modification occurred such as 
glycosylation and signal peptide cleavage in the expression cells.

\subsection{Cell adhesion activity of c-SPH}

Cell adhesion is essential in the immune system of invertebrates [27]. Many cell adhesive extracellular matrix, blood, and cell surface proteins contain the RGD tripeptide motif characteristic for integrin binding [28]. In contrast to the cell adhesion activity of crayfish granular cells, which is present only in HLS [29], the cell adhesion activity in shrimp total hemocytes was detected in wells coated with HLS or plasma (data not shown). Shrimp peroxinectin contributes to a partial adhesion activity in proPO activated HLS and the RGD/KGD motif of the peroxinectin may be involved in the cell adhesion activity [30,31]. The presence of two RGD motifs of shrimp $\beta$-glucan binding protein suggest that it may be a potential candidate in response to the adhesion activity in plasma [32,33]. However, there is no RGD motif in the shrimp c-SPH. According to the analysis of crayfish masquerade-like molecule, it is the SP-like domain that is involved in the cell adhesion activity [8]. The cell adhesion activity of the shrimp c-SPH was not inhibited by a polyclonal antibody against the synthetic 14-mers oligopeptide, i.e. $\mathrm{N}_{-}{ }^{52} \mathrm{RPVVERCPDQKECC}{ }^{85}-\mathrm{C}$, in the clip domain. This implies the consistency of the adhesive region of SP-like domain in crayfish (data not shown). In summary, the adhesion activity between hemocytes and c-SPH was characterized as dosedependent, calcium-dependent, RGD-independent, and possibly SP-like domain-involved. Whether the calcium-binding loop in SP domain involves the calcium-dependent manner or not needs further study. Cell adhesion is the first step in many cellular responses in innate immunity that includes hemocyte spreading, nodule formation, encapsulation, hemocyte aggregation, and phagocytosis. In crayfish, the whole mas-like protein rather than the SPlike domain alone can serve as an opsonin to enhance bacterial clearance [7]. However, when we injected Vibrio vulnificus pre-incubated with PmocSPH into shrimp, no opsonization activity of cSPH was observed (data not shown). In the model proposed in tobacco hornworm, SPH interacts with immulectin-2, proPO, and prophenoloxidase (proPO) activating protease (PAP) [11]. Recently, Ling and $\mathrm{Yu}$ [34] found that proPO and $\mathrm{PO}$ bind to the hemocyte surface and that the activation of proPO initiates hemocyte melanization in tobacco horn- worm. The binding of proPO/PO to the hemocyte surface may require a direct interaction between proPO/PO and hemocyte surface receptors or may involve other accessory proteins. Although the possibility of the direct interaction of proPO/PO and hemocyte cannot be excluded, the hemocyte adhesion activity of shrimp c-SPH may contribute to the potential role of c-SPH as a shuttle between proPO/PO and hemocytes, enhancing the antimicrobial activity of the host and localizing the PO activity to the hemocyte-targeting site.

According to the genome sequences of $D$. melanogaster, D. pseudoobscura, Anopheles gambiae, and Apis mellifera, more than one c-SPH isoform were identified in these species. There are two cSPHs (mas-like and low molecular mass mas-like molecules) found in granules of crayfish hemocyte and three c-SPHs in Manduca sexta. In the genome of the fruit fly, $13 \mathrm{c}-\mathrm{SPH}$ sequences have been identified. Questions arise as to why there are so many catalytically inactive enzymes, what roles they play and how they proceed. Are there many c-SPH isoforms in shrimp? Further study is required in order to address these questions.

\section{Acknowledgements}

We thank Prof. Yu-Chan Chao, Institute of Molecular Biology, Academia Sinica, for kindly providing the baculovirus transfer vector pABhRpX and Prof. Huai-Jen Tsai, Institute of Molecular and Cell Biology, National Taiwan University, for primers to detect beta-tubulin gene. This work was supported financially by the $\mathrm{Na}$ tional Science Council, Republic of China with grant number NSC 94-2313-B-002-069 and 93-2311B-016-001.

\section{References}

[1] Murugasu-Oei B, Rodrigues V, Yang X, Chia W. Masquerade: a novel secreted serine protease-like molecule is required for somatic muscle attachment in the Drosophila embryo. Genes Dev 1995;9:139-54.

[2] Iwanaga S, Kawabata S, Muta T. New types of clotting factors and defense molecules found in horseshoe crab hemolymph: their structures and functions. J Biochem (Tokyo) 1998;123:1-15.

[3] Muta T, Hashimoto R, Miyata T, Nishimura H, Toh Y, Iwanaga S. Proclotting enzyme from horseshoe crab hemocytes. cDNA cloning, disulfide locations, and subcellular localization. J Biol Chem 1990;265:22426-33. 
[4] Jiang H, Kanost MR. The clip-domain family of serine proteinases in arthropods. Insect Biochem Mol Biol 2000;30:95-105.

[5] Piao S, Song YL, Kim JH, Park SY, Park JW, Lee BL, et al. Crystal structure of a clip-domain serine protease and functional roles of the clip domains. Embo J 2005;24: 4404-14.

[6] Kawabata S, Tokunaga F, Kugi Y, Motoyama S, Miura Y, Hirata $\mathrm{M}$, et al. Limulus factor $\mathrm{D}$, a 43-kDa protein isolated from horseshoe crab hemocytes, is a serine protease homologue with antimicrobial activity. FEBS Lett 1996; 398:146-50.

[7] Lee SY, Söderhäll K. Characterization of a pattern recognition protein, a masquerade-like protein, in the freshwater crayfish Pacifastacus leniusculus. J Immunol 2001;166:7319-26.

[8] Huang TS, Wang H, Lee SY, Johansson MW, Söderhäll K, Cerenius L. A cell adhesion protein from the crayfish Pacifastacus leniusculus, a serine proteinase homologue similar to Drosophila masquerade. J Biol Chem 2000;275: 9996-10001.

[9] Kwon TH, Kim MS, Choi HW, Joo CH, Cho MY, Lee BL. A masquerade-like serine proteinase homologue is necessary for phenoloxidase activity in the coleopteran insect, Holotrichia diomphalia larvae. Eur J Biochem 2000;267:6188-96.

[10] Lee KY, Zhang R, Kim MS, Park JW, Park HY, Kawabata $\mathrm{S}$, et al. A zymogen form of masquerade-like serine proteinase homologue is cleaved during pro-phenoloxidase activation by $\mathrm{Ca}^{2+}$ in coleopteran and Tenebrio molitor larvae. Eur J Biochem 2002;269:4375-83.

[11] Yu XQ, Jiang H, Wang Y, Kanost MR. Nonproteolytic serine proteinase homologs are involved in prophenoloxidase activation in the tobacco hornworm, Manduca sexta. Insect Biochem Mol Biol 2003;33:197-208.

[12] Zhang G, Lu ZQ, Jiang H, Asgari S. Negative regulation of prophenoloxidase (proPO) activation by a clip-domain serine proteinase homolog (SPH) from endoparasitoid venom. Insect Biochem Mol Biol 2004;34: 477-83.

[13] Asgari S, Zhang G, Zareie R, Schmidt O. A serine proteinase homolog venom protein from an endoparasitoid wasp inhibits melanization of the host hemolymph. Insect Biochem Mol Biol 2003;33:1017-24.

[14] Buda ES, Shafer TH. Expression of a serine proteinase homolog prophenoloxidase-activating factor from the blue crab, Callinectes sapidus. Comp Biochem Physiol B Biochem Mol Biol 2005; 140:521-31.

[15] Simser JA, Mulenga A, Macaluso KR, Azad AF. An immune responsive factor D-like serine proteinase homologue identified from the American dog tick, Dermacentor variabilis. Insect Mol Biol 2004;13:25-35.

[16] Sricharoen S, Kim JJ, Tunkijjanukij S, Söderhäll I. Exocytosis and proteomic analysis of the vesicle content of granular hemocytes from a crayfish. Dev Comp Immunol 2005;29:1017-31.

[17] Veiga AB, Ribeiro JM, Guimarães JA, Francischetti IM. A catalog for the transcripts from the venomous structures of the caterpillar Lonomia obliqua: identification of the proteins potentially involved in the coagulation disorder and hemorrhagic syndrome. Gene 2005;355:11-27.
[18] Falquet L, Pagni M, Bucher P, Hulo N, Sigrist CJ, Hofmann $\mathrm{K}$, et al. The PROSITE database, its status in 2002. Nucleic Acids Res 2002;30:235-8.

[19] Altschul SF, Madden TL, Schäffer AA, Zhang J, Zhang Z, Miller W, et al. Gapped BLAST and PSI-BLAST: a new generation of protein database search programs. Nucleic Acids Res 1997;25:3389-402.

[20] Thompson JD, Gibson TJ, Plewniak F, Jeanmougin F, Higgins DG. The CLUSTAL_X windows interface: flexible strategies for multiple sequence alignment aided by quality analysis tools. Nucleic Acids Res 1997;25:4876-82.

[21] Kumar S, Tamura K, Nei M. MEGA3: Integrated software for Molecular Evolutionary Genetics Analysis and sequence alignment. Brief Bioinform 2004;5:150-63.

[22] Bradford MM. A rapid and sensitive method for the quantitation of microgram quantities of protein utilizing the principle of protein-dye binding. Anal Biochem 1976; 72:248-54

[23] Klein SL, Strausberg RL, Wagner L, Pontius J, Clifton SW, Richardson P. Genetic and genomic tools for Xenopus research: The NIH Xenopus initiative. Dev Dyn 2002;225: 384-91.

[24] Ross J, Jiang H, Kanost MR, Wang Y. Serine proteases and their homologs in the Drosophila melanogaster genome: an initial analysis of sequence conservation and phylogenetic relationships. Gene 2003;304:117-31.

[25] Lo CF, Ho C, Chen CH, Liu KF, Chiu YL, Yeh PY, et al. Detection and tissue tropism of white spot syndrome baculovirus (WSBV) in captured brooders of Penaeus monodon with a special emphasis on reproductive organs. Dis Aquat Org 1997;30:53-72.

[26] Song YL, Liu JJ, Chan LC, Sung HH. Glucan-induced disease resistance in tiger shrimp (Penaeus monodon). Dev Biol Stand 1997;90:413-21.

[27] Johansson MW. Cell adhesion molecules in invertebrate immunity. Dev Comp Immunol 1999;23:303-15.

[28] Ruoslahti E. RGD and other recognition sequences for integrins. Annu Rev Cell Dev Biol 1996;12:697-715.

[29] Johansson MW, Söderhäll K. Isolation and purification of a cell adhesion factor from crayfish blood cells. J Cell Biol 1988;106:1795-803.

[30] Johansson MW, Lind MI, Holmblad T, Thörnqvist PO, Söderhäll K. Peroxinectin, a novel cell adhesion protein from crayfish blood. Biochem Biophys Res Commun 1995;216:1079-87.

[31] Sritunyalucksana K, Wongsuebsantati K, Johansson MW, Söderhäll K. Peroxinectin, a cell adhesive protein associated with the proPO system from the black tiger shrimp, Penaeus monodon. Dev Comp Immunol 2001;25:353-63.

[32] Sritunyalucksana K, Lee SY, Söderhäll K. A beta-1,3-glucan binding protein from the black tiger shrimp, Penaeus monodon. Dev Comp Immunol 2002;26:237-45.

[33] Cheng W, Liu CH, Tsai CH, Chen JC. Molecular cloning and characterisation of a pattern recognition molecule, lipopolysaccharide-and beta-1,3-glucan binding protein (LGBP) from the white shrimp Litopenaeus vannamei. Fish Shellfish Immunol 2005;18:297-310.

[34] Ling E, Yu XQ. Prophenoloxidase binds to the surface of hemocytes and is involved in hemocyte melanization in Manduca sexta. Insect Biochem Mol Biol 2005;35:1356-66. 